TITLE:

\title{
Shunt flow of arteriovenous fistulas from plantar artery.
}

$\operatorname{AUTHOR}(\mathrm{S})$ :

Yoshida, Y; Fujita, M

\section{CITATION:}

Yoshida, Y ... [et al]. Shunt flow of arteriovenous fistulas from plantar artery.. Phlebology 2011, 26(1): 32-34

ISSUE DATE:

2011-02

URL:

http://hdl.handle.net/2433/137221

\section{RIGHT:}

This is the final draft, after peer-review, of a manuscript published in Phlebology. The definitive version, detailed above, is available online at www.rsmjournals.com.; This is not the published version. Please cite only the published version.; この論文は出版社版であり ません。引用の際には出版社版をご確認ご利用ください。 


\section{Original article}

\section{Shunt flow of arteriovenous fistulas from plantar artery}

Short title: Visualization of arteriovenous fistulas

by

Yuki Yoshida, Tatsuro Sato and Masatoshi Fujita

from

SATO Clinic of Vascular Surgery, Kyoto, Japan (Y. Y., T. S.)

Human Health Sciences, Kyoto University Graduate School of Medicine, Kyoto, Japan (M. F.)

Disclosures: None.

Keywords: Doppler ultrasound; duplex ultrasound; endoveneous laser surgery; recurrence; varicose veins

Total word count of text (excluding abstract): 1,346 words

Correspondence to: Masatoshi Fujita, MD, FAHA, FACC, FESC

Professor

Human Health Sciences

Kyoto University Graduate School of Medicine

53 Kawaharacho, Shogoin, Sakyo-ku

Kyoto 606-8507, Japan

TEL: +81-75-751-3932

FAX: +81-75-751-3909

E-mail: mfujita@kuhp.kyoto-u.ac.jp 


\section{Abstract}

Objectives: The purpose of this study was to visualize the shunt flow of arteriovenous fistulas (AVFs) passing toward the top side of the foot from the plantar artery.

Methods: Color-flow duplex Doppler ultrasonography was performed in 112 patients who consulted our outpatient clinic with varicose veins and/or symptoms such as foot edema, dullness, cramp and coldness. Thirteen age-and sex-matched healthy subjects served as controls.

Results: AVFs were detected in 86 of 112 patients (77\%). They were also detected in 10 (77\%) of 13 healthy subjects. The shunt flow pattern consisted of two phases of flow corresponding to systole and diastole, and the diastolic fraction of time-velocity integral was larger, although the peak flow velocity in systole was higher than that in diastole.

Conclusions: Color-flow duplex Doppler ultrasonography is useful for noninvasive visualization of the shunt flow of AVFs connecting the plantar artery with the venous arch of the top side of the foot. (154 words) 


\section{Introduction}

Arteriovenous fistulas (AVFs) in patients with varicose veins have been documented by visual observation during surgery with use of high-powered microscopes or magnifying lenses. ${ }^{1-6}$ In 1987, Haimovici reported a precise distribution of AVFs, but most of AVFs were observed along the medial aspect of the calf. ${ }^{6}$ Here, we propose a new approach for the detection of AVFs passing toward the top side of the foot from the plantar artery using color-flow duplex Doppler ultrasonography.

\section{Methods}

We studied 112 consecutive patients (21 men and 91 women, aged 18 to 88 years (mean 60.5) who consulted our outpatient clinic with varicose veins and/or symptoms such as foot dullness, coldness, edema, cramp, and ulceration. Seventy-four patients had primary varicose veins without any previous operative procedures. Twenty-six patients had undergone surgical ligation, stripping or endovenous laser surgery for the incompetent great and/or small shaphenous veins. Among 26 patients, 5 patients had recurrent varicositis and 21 patients complained of foot coldness, edema, clamp, and ulceration despite successful operative treatment. The remaining 12 patients had symptoms without varicose veins. Thirteen age-and sex-matched healthy subjects served as controls. This study was approved by the institutional human ethical committee. 
After footbath (temperature 38 to $40^{\circ} \mathrm{C}$, for 5 minutes), all subjects were examined using color-flow duplex Doppler ultrasonography (LOGIQ P5 Ultrasound System; GE Healthcare, USA) with a $12 \mathrm{MHz}$ transducer. The ultrasound beam was placed perpendicularly just below the venous arch of the top side of the foot, and the first to the fourth interosseous space was scanned from the base of the toes to the venous arch in the standing position (Figure 1). When the AVFs were detected on the color Doppler ultrasonography, the sample volume was located on the AVF, and blood flow velocity was recorded using the pulse wave Doppler ultrasonography. Furthermore, blood flow velocity and diameter of the dorsalis pedis artery at the proximal part of the first interosseous space were measured before and after footbath.

\section{Results}

The AVFs were visualized with the color Doppler ultrasonography in 86 (77\%) of 112 patients and they were also detected in 10 (77\%) of 13 health subjects (Figure 2). Blood flow velocity was successfully recorded with the pulsed wave Doppler ultrasonography. The number of AVFs was one to four in the one foot, usually symmetric in both feet. The size of AVFs ranged from less than $1.0 \mathrm{~mm}$ to $6.0 \mathrm{~mm}$ in diameter. The flow pattern of AVFs consisted of two phases corresponding to the systole and diastole. Diastolic flow velocity was predominant in the time-velocity integral, although the peak flow velocity in systole was higher than that in diastole (Figure 3). There were no significant differences in the blood flow 
velocity and diameter of the dorsalis pedis artery before and after footbath (Figure 4).

\section{Discussion}

The pathogenesis of varicose veins is recognized as the result of primary valvular insufficiency of the great and small saphenous veins and incompetence of the perforating veins. AVFs were postulated as one of the underlying causes of varicose veins. Although the presence of AVFs in patients with varicose veins was documented, the distribution was limited from the ankle to the thigh. ${ }^{6}$ To the best of our knowledge, the presence of AVFs on the top of the foot has not been reported until now.

Color-flow duplex Doppler ultrasonography enabled us to visualize the shunt flow of AVFs arising from the plantar artery. In the majority of cases, the AVFs are closed under the normal temperature. However, blood flow through the fistula appears in the presence of relatively high temperature. Therefore, we attempted to detect the AVFs after footbath for an optimal recording. In this study, the prevalence of AVFs in the top side of the feet was $77 \%$. The AVFs are natively preexistent as natural vascular channels connecting the artery with venous circulation. ${ }^{6} \quad$ They allow the arterial blood to pass directly into the veins bypassing the capillary bed. However, if the shunt flow is persisting or occurring relatively often, this condition predisposes the abnormal pathological milieu. ${ }^{6}$

Recently, endovenous laser surgery has been introduced as a minimal invasive 
alternative of surgical ligation and stripping for varicose veins. ${ }^{7-9}$ The treatment of AVFs on the top side of the foot with the new therapeutic modality is now being studied, since the arteriovenous shunting is logically eliminated. Implications of AVFs on the foot should be investigated in future studies, focusing on the relationships with clinical symptoms and signs.

In conclusion, with use of color-flow duplex Doppler ultrasonography, visualization of the shunt flow of arteriovenous fistulas from the plantar artery toward venous arch of the top side of foot was successful in about three quarters of individuals irrespective of clinical symptoms and signs of the foot.

\section{Acknowledgments}

The authors would like to thank Ms. Yukiko Okumura for her meritorious secretary assistance. 


\section{References}

1. Piulachs P, Vidal-Barraquer F. Pathogenic study of varicose veins. Angiology $1953 ; 4: 59-100$

2. Haimovici H, Steinman C, Caplan LH. Angiographic evaluation of arteriovenous shunting in peripheral vascular diseases. Radiology 1966;87:696-704

3. Schalin L. Arteriovenous communications in varicose veins localized by thermography and identified by operative microscopy. Acta Chir Scand 1981;147:409-20

4. Haimovici H. Arteriovenous shunting in varicose veins: its diagnosis by Doppler ultrasound flow detector. J Vasc Surg 1985;2:684-91

5. Baron HC, Cassaro S. The role of arteriovenous shunts in the pathogenesis of varicose veins. J Vasc Surg 1986;4:124-8

6. Haimovici H. Role of precapillary arteriovenous shunting in the pathogenesis of varicose veins and its therapeutic implications. Surgery 1987;101:515-22

7. Theivacumar NS, Beale RJ, Mavor Al, Gough MJ. Initial experience in endovenous laser ablation (EVLA) of varicose veins due to small saphenous vein reflux. Eur J Vasc Surg 2007;33:614-8

8. Gibson KD, Ferris BL, Polissar N, Neradilec B, Pepper D. Endovenous lazar treatment of the small saphenous vein: efficacy and complications. J Vasc Surg 2007;45:795-801

9. Darwood RJ, Theivacumar NS, Dellagrammaticas D, Mavor AID, Gough MJ. 
Randomized clinical trial comparing endovenous laser ablation with surgery for the treatment of primary great saphenous varicose veins. Br J Surg 2008;95:294-301 


\section{Figure Legends}

Figure 1 Duplex Doppler ultrasonographic approach. The ultrasound transducer was placed perpendicularly at the site of the venous arch of the top side of the foot in the standing position.

Figure 2 Color Doppler ultrasonographic image of an AVF. Red signal shows an AVF flow into the venous arch of the top side of the foot from the plantar artery.

Figure 3 Flow pattern of an AVF. Biphasic flow velocity pattern was obtained with the pulse wave Doppler ultrasonography.

Figure 4 Blood flow velocity of the dorsalis pedis artery before and after footbath. 